\section{On the Potential Public Health Consequences of "Xenophobic" Political Strategies and Policies}

Dear Editor:

Quebecers have been called upon by the Parti Québécois (PQ) government to "come together" around our common values and enact legislation that would prohibit provincial government employees (e.g., hospital workers, judges, police officers, school teachers, daycare workers, university staff) from wearing overt religious symbols (e.g., the kippa, the hijab, jewelry bearing a large Star of David or cross). ${ }^{1}$ The PQ argues that this legislation will "preserve social peace" and "contribute to integration and social cohesion". The term social cohesion draws on sociological work about the importance of adhering to and reinforcing common values for social well-being (e.g., social stability). Political pundits have argued that the proposed legislation is a tactic to polarize voters, gain support in upcoming elections and draw attention away from other issues (e.g., the provincial budget).

Whatever the primary aim of the proposed legislation, this political strategy can have at least two detrimental effects on public health. First, the groups targeted by these policies may experience poorer well-being. Many news reports have centered on acts of aggression toward Muslim women who wear the hijab, with other discussions centering on gender equality, and the fear of "Islamisation". Muslim women concerned about prejudice and discrimination are likely to experience strong negative emotions (e.g., sadness, anger and fear) and engage in unhealthy coping mechanisms (e.g., rumination). ${ }^{2}$ It is indeed difficult to imagine that no negative consequences would emerge from an elected government's sudden decision that women employees must adhere to a dress code that would require them to expose parts of their bodies they otherwise would not.

Second, the proposed policy may have negative health consequences for Quebecers at large. The PQ's language suggests value competition: those who do not conform to the norm - with regards to beliefs and dress-style - are not "with us" in supporting our common values. Research on interpersonal perception and relations suggests that perceived competition with others engenders perceptions that others are less warm, kind and trustworthy. ${ }^{3}$ In turn, perceiving other social groups as lacking warmth is associated with angry and fearful emotional responses, and with attacking and excluding behaviours. ${ }^{4}$ Ramping up negative perceptions and responses toward others may therefore be detrimental for actual and perceived social cohesion.

Individuals who perceive less social cohesion also feel less safe. ${ }^{5}$ Feeling unsafe is associated with a range of negative health out- comes for adults, including poorer sleep quality, less physical activity, and poorer overall health. ${ }^{6,7}$ For youth, adult and youth perceptions of a lack of safety are associated with lower levels of physical activity and increased screen time. ${ }^{8,9}$

This political strategy is therefore likely to have serious public health and economic costs. In the UK, it is estimated that the social and health-related economic costs of feeling unsafe or fearfulness are in the hundreds of millions of pounds. ${ }^{10}$ Researchers interested in public health would be well suited to dedicate increased attention to the potential public health consequences of political strategies and policies that promote a set of "common values" that some would argue is axed on xenophobia.

Carolyn Côté-Lussier, PhD, Department of Social and Preventive Medicine, Université de Montréal, Montréal, QC; Research Centre, Centre Hospitalier Universitaire (CHU) Sainte-Justine, Montréal, QC

Tracie A. Barnett, PhD, Research Centre, Centre Hospitalier Universitaire (CHU) Sainte-Justine, Montréal, QC; Department of Exercise Science, Concordia University, Montréal, QC

Correspondence: Carolyn Côté-Lussier, Research Centre, CHU Sainte-Justine, 5757 Decelles, Suite 100, Montréal, QC H3S 2C3, Tel: 514-345-4931, ext. 3232, E-mail: carolyn.cote.lussier@umontreal.ca

Disclaimer: The views expressed herein are those of the authors and do not necessarily reflect those of host institutions and funding bodies.

Funding: CCL holds a Fonds de recherche du Québec - Société et culture postdoctoral bursary. TB holds a Fonds de recherche santé Québec Research Scholar award.

\section{REFERENCES}

1. Gouvernement du Québec. Parce que nos valeurs, on y croit. Gouvernement du Québec, 2013. Available at: http://www.nosvaleurs.gouv.qc.ca/medias/ pdf/Valeurs_depliant_version_courte.pdf (Accessed September 30, 2013).

2. Rodriguez Mosquera PM, Khan T, Selya A. Coping with the $10^{\text {th }}$ anniversary of 9/11: Muslim Americans' sadness, fear, and anger. Cogn Emot 2013;27(5):932-41.

3. Fiske ST, Cuddy AJ, Glick P, Xu J. A model of (often mixed) stereotype content: Competence and warmth respectively follow from perceived status and competition. J Pers Soc Psychol 2002;82(6):878-902.

4. Cuddy AJC, Fiske ST, Glick P. The BIAS map: Behaviors from intergroup affect and stereotypes. J Pers Soc Psychol 2007;92(4):631-48.

5. Jackson J. Experience and expression: Social and cultural significance in the fear of crime. Br J Criminol 2004;44(6):946-66.

6. Hill TD, Burdette AM, Hale L. Neighborhood disorder, sleep quality, and psychological distress: Testing a model of structural amplification. Health Place 2009;15(4):1006-13.

7. Ross CE, Mirowsky J. Neighborhood disadvantage, disorder, and health. J Health Soc Behav 2001;42(3):258-76.

8. Carson V, Janssen I. Neighborhood disorder and screen time among 10-16 year old Canadian youth: A cross-sectional study. Int J Behav Nutr Phys Act 2012;9(1):66-76.

9. Weir LA, Etelson D, Brand DA. Parents' perceptions of neighborhood safety and children's physical activity. Prev Med 2006;43(3):212-17.

10. Dolan P, Peasgood T. Estimating the economic and social costs of the fear of crime. Br J Criminol 2007;47(1):121-32. 